\title{
Nociceptin Measurement
}

National Cancer Institute

\section{Source}

National Cancer Institute. Nociceptin Measurement. NCI Thesaurus. Code C154744.

The determination of the amount of nociceptin present in a sample. 